\title{
LIMITATIONS OF CROSS TABLE PRONE LATERAL X-RAY/INVERTOGRAM IN DIAGNOSING OF TYPES OF ANORECTAL MALFORMATIONS
}

\begin{tabular}{ll}
\hline $\begin{array}{ll}\text { General Surgery } \\
\text { Dr. Renu } \\
\text { Kushwaha }\end{array}$ & $\begin{array}{l}\text { Assistant Professor, Department Of Pediatric Surgery, B.R.D Medical College } \\
\text { Gorakhpur. }\end{array}$ \\
\hline $\begin{array}{l}\text { Dr. Santosh } \\
\text { Kushwaha }\end{array}$ & Assistant Professor, Department Of General Surgery, B.R.D Medical College Gorakhpur. \\
\hline $\begin{array}{l}\text { Dr. Rachna } \\
\text { Bhatnagar }\end{array}$ & Professor, Department Of Pediatrics, B.R.D Medical College, Gorakhpur. \\
\hline Dr. U.C Singh & Professor, Department OfGeneral Surgery, B.R.D Medical College Gorakhpur. \\
\hline Dr. Deepak Singh & Assistant Professor, Department Of General Surgery, B.R.D Medical College Gorakhpur. \\
\hline Dr. Mukul Singh* & $\begin{array}{l}\text { Assistant Professor, Department Of General Surgery, B.R.D Medical College Gorakhpur. } \\
* \text { Corresponding Author }\end{array}$ \\
\hline
\end{tabular}

\section{ABSTRACT}

INTRODUCTION: Anorectal malformation is the very common congenital malformation with the incidence of 1 in $5000(1,2)$. The diagnosis is made on perineal examination which is further corroborated by cross table prone lateral x-ray or invertogram to find out the level of anorectal atresia. The cross table prone lateral x-ray is considered better investigation tool as compared to invertogram for demonstration of the level of rectal atresia in neonates. In prone cross table lateral x-ray, effect of gravity is negated, positioning of the baby is more comfortable and the rectal gas shadow is better delineated. AIM:To evaluate the sensitivity and specificity of cross table prone lateral x-ray in labelling a patient of anorectal malformation as high or low. MATERIALAND METHODS: The study was conducted in retrospective manner. Radiological materials, clinical and operative records of the neonates with anorectal malformation operated in Department of Surgery, Pediatric Surgery unit, BRD Medical College over a period of 2 years (June 2017 to July 2019) were retrieved. Total 100 neonates with anorectal malformation were admitted in our hospital during this time frame. Out of these patients, colostomy was done in 79 patients, anoplasty was performed in 18 cases. Two patients underwent primary posterior sagittal anorectoplasty while 1 patient had ileostomy done. During this study, we came across four unusual cases of low anorectal malformation where the x-ray picture did not coincide with the clinical diagnosis. CONCLUSION: Diagnosis of anorectal malformation is clinical but to diagnose the type of anorectal malformation it requires both clinical as well as radiological workup. In case of diagnostic dilemma, our clinical interpretation should lead the diagnosis as none of the $\mathrm{x}$-ray modality has $100 \%$ sensitivity.

\section{KEYWORDS}

Anorectal Malformations, Limitations, Cross Table Prone Lateral X-ray ,invertogram,diagnosis.

\section{INTRODUCTION:}

Anorectal malformation is the very common congenital malformation with the incidence of 1 in $5000(1,2)$. The diagnosis is made on perineal examination which is further corroborated by cross table prone lateral $\mathrm{x}$-ray or invertogram to find out the level of anorectal atresia. The cross table prone lateral $\mathrm{x}$-ray is considered better investigation tool as compared to invertogram for demonstration of the level of rectal atresia in neonates. In prone cross table lateral $x$-ray, effect of gravity is negated, positioning of the baby is more comfortable and the rectal gas shadow is better delineated.

Anorectal malformations are classified into high, intermediate and low malformations based on both clinical and radiological findings. High anorectal malformations usually present with history of meconuria and in cross table $x$-ray the rectal gas shadow is above the coccyx $(3,4)$. Low anorectal malformation typically shows perineal bulge, meconium pearls (4) and/or anocutaneous fistula and this presents in $\mathrm{X}$ ray as rectal gas shadow below the coccyx $(3,4)$. The prognosis of low anorectal malformation is excellent with normal voiding pattern (3). The prognosis of high anorectal malformation depends upon associated anomalies in genitourinary and cardiovascular system and sacral agenesis (5). Cross table x-ray plays an important role in determining the type of malformations though there are certain fallacies associated with it.

We present series of 4 patients of anorectal malformation where their clinical presentation did not match with the $\mathrm{x}$-ray picture and created diagnostic dilemma regarding their management. We came across 3 cases of low anorectal malformation which were diagnosed as high anomalies on cross table $\mathrm{x}$-ray and 1 patient of high anorectal anomaly which mimicked like a low malformation.

AIM:

To evaluate the sensitivity and specificity of cross table prone lateral $\mathrm{x}$ - ray in labelling a patient of anorectal malformation as high or low.

\section{MATERIALAND METHODS:}

The study was conducted in retrospective manner. Radiological materials, clinical and operative records of the neonates with anorectal malformation operated in Department of Surgery, Pediatric Surgery unit, BRD Medical College over a period of 2 years (June 2017 to July 2019) were retrieved. Total 100 neonates with anorectal malformation were admitted in our hospital during this time frame. Out of these patients, colostomy was done in 79 patients, anoplasty was performed in 18 cases. Two patients underwent primary posterior sagittal anorectoplasty while 1 patient had ileostomy done. During this study, we came across four unusual cases of low anorectal malformation where the $\mathrm{x}$-ray picture did not coincide with the clinical diagnosis.

\section{CASE REPORT 1:}

A four day male baby presented to Department of Surgery, Paediatric surgery Unit, BRD Medical College, Gorakhpur with absent anal opening. Parents did not reveal any history suggestive of meconuria. On examination there was abdominal distention and meconium pearls were present over the perineum. On crying there was a clear cut bulge at the perineum. Cross table x-ray was done but surprisingly it revealed rectal gas shadow above the coccyx which was suggestive of high anorectal malformation. X-ray was repeated after 24 hour which again showed high type of anomaly. Despite of this diagnostic dilemma, pt was taken for anoplasty. Just after incising over the anal bulge in midline, we came across the rectal pouch. Anoplasty was performed in usual fashion. Postoperative period was uneventful and the pt was discharged in a satisfactory condition.

\section{CASE REPORT 2:}

A two day male baby presented to BRD Medical College, Surgery Department, Paediatric Surgery unit as a case of anorectal malformation. There was no history of meconurea. On examination, 
there was moderate abdominal distension, meconium pearls were absent and there was no perineal bulge. Cross table x-ray was taken which was suggestive of high anorectal malformation. Based on these presentations and $\mathrm{x}$-ray findings, patient underwent laparotomy through left lower transverse incision. Around $3 \mathrm{~cm}$ anterior wall of the rectum was sloughed out but surprisingly there was no peritoneal contamination. Excision of the necrotic part with primary repair of the defect and high loop sigmoid colostomy was made. On postoperative day 2, patient started passing stool from the colostomy as well as from an anocutaneous fistula over the median raphe so it turned out to be a case of low anorectal malformation.

\section{CASE REPORT 3:}

A four day male baby was referred to our center as a case of anorectal malformation with distended abdomen. On examination meconium pearls were present at the median raphe. In erect $\mathrm{x}$-ray abdomen there was pneumoperitoneum and in cross table $\mathrm{x}$-ray, it was high anorectal malformation. As patient presented as perforation peritonitis, we had no other option except doing laparotomy which was performed through left lower quadrant. Anterior wall of the rectum had been sloughed out and there was gross peritoneal contamination. Margin was freshened and primary closure of the rent was done with proximal high sigmoid loop colostomy. His postoperative period was uneventful. Stoma started functioning on 2nd postoperative day and patient was allowed orally. Distal colostogram was done on postoperative day 14 and that was suggestive of low anorectal malformation.

\section{CASE REPORT 4:}

A three day male baby was brought to us with absent anal opening and huge abdominal distention. History of meconurea was present. There was no anocutaneous fistula or meconium pearls. These findings led us to make the diagnosis of high anomaly but surprisingly the cross table $\mathrm{x}$-ray showed rectal gas shadow well below the level of coccyx. This $\mathrm{x}$ ray finding persisted even in repeat $\mathrm{x}$-ray film. We did high sigmoid colostomy in view of gross abdominal distention. On the post operative day 14, we performed pressure augmented distal colostogram which showed termination of the rectal pouch above the level of coccyx and finally the diagnosis of high anorectal malformation was made.

\section{DISCUSSION:}

Cross table prone lateral $\mathrm{x}$-ray is now days considered the investigation of choice in the neonate with anorectal malformation to know the level of rectal atresia. But there are certain prerequisites which have to be fulfilled before doing any cross table x-ray (6). Ideally cross table prone x-ray film should be delayed for at least 12 to 24 hours of life. This is to allow the rectal gas to ascend upto the maximum level of the rectal pouch. The baby should be positioned in the prone position for at least 3 minutes before shooting an x-ray. This much delay allows rectal gas to displace meconium and rise to the termination of the rectal pouch. The accurate positioning of the baby in cross table lateral prone view is also very important to insure superimposition of the ossification centers of the pubic bones and ischial bones. The hips are placed in slightly extended position so that the femoral shadow can not hinder with pubic ossification center.

Even with above precautions, erroneous interpretation of the cross table $\mathrm{x}$-ray findings is possible (6). Tight sphincteric muscle complex or presence of thick meconium plug in the rectal pouch could be the possibility where the gas cannot displace the meconium. Sometimes, gas escapes out through an anocutaneous fistula and $\mathrm{x}$-ray may mimick the picture of high anorectal malformation.

In our study group, the case 1 presented as a low anomaly but in x-ray the gas shadow was well above the coccyx. These contradictory findings could be attributed to spasm of the sphincteric complex or thick meconium plug in the rectal pouch. So the rectal gas could not find the way to ascend up and the $\mathrm{x}$-ray picture was depictive of high anorectal malformation.

The case 2 presented as a case of high anorectal malformation both clinically as well as radiologically but later on it turned out to be a case of low anomaly. Even the sloughed out rectal pouch did not cause pneumoperitoneum. Thick meconium plug in the rectal pouch was the possible reason for the erroneous interpretation of the $\mathrm{x}$-ray. This did not let the rectal gas ascend up as well as enter the peritoneal cavity. After retrieval of the thick meconium paste from the pouch, the gas and the thin meconium could find their way upto the termination of the rectal pouch which was well below the coccyx and this further manifested in the form of decompressing anocutaneous fistula.

The 3rd case of low anorectal malformation presented with pneumoperitoneum in erect $\mathrm{x}$-ray but cross table $\mathrm{x}$-ray could not reveal low malformation. The rectal gas could have escaped in the peritoneal cavity through the perforation site so there was not enough gas in the rectum to mount adequate pressure for delineation of the extent of the rectal pouch.

Our 4th case was a different one as clinically it was a high malformation but cross table $\mathrm{x}$-ray depicted it to be a low anomaly. This unusual presentation can be attributed to grossly distended rectum mounting enough pressure to cause erroneously low lying pouch. During colostomy, meconium was aspirated from the distal pouch and excess pressure was relieved and subsequently distal colostogram showed high malformation.

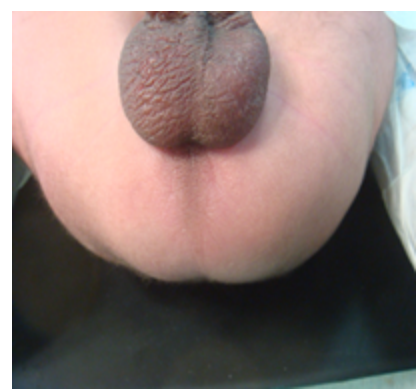

FIGURE-1 ARM

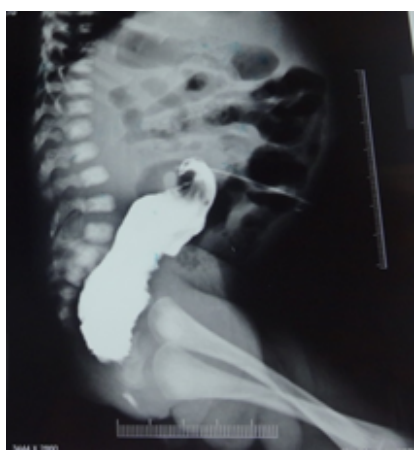

FIGURE-2 INVERTOGRAM

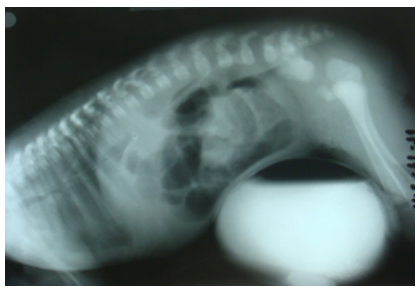

FIGURE-3 CROSS TABLE PRONE LATERAL X-RAY

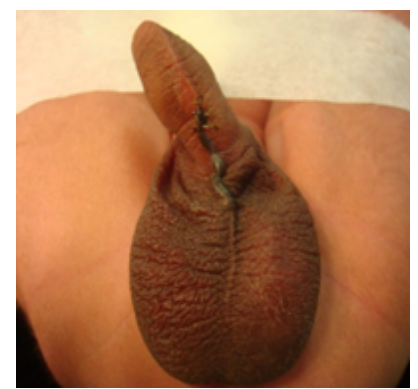

FIGURE-4 


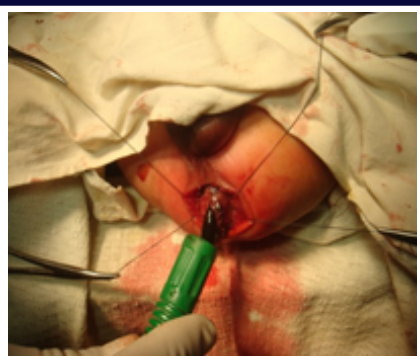

\section{FIGURE-5}

\section{CONCLUSION:}

Diagnosis of anorectal malformation is clinical but to diagnose the type of anorectal malformation it requires both clinical as well as radiological workup. In case of diagnostic dilemma, our clinical interpretation should lead the diagnosis as none of the $\mathrm{x}$-ray modality has $100 \%$ sensitivity. Had we relied upon the $\mathrm{x}$-ray, we could have done colostomy in our first case of low malformation and could have tried anoplasty in the 4th case which was actually a high anomaly and have added to the morbidity.

Moreover accurate timing and positioning of the baby is very important for precise and exact value of the level of anorectal atresia in cross table x-ray. The above mentioned four cases of low anorectal malformations in our study group are the examples of unusual presentations of the cross table x-ray and they give an insight of the limitations of the cross table $\mathrm{x}$-ray.

\section{REFERENCES:}

Martucciello G: Genetics of anorectal malformation. In Anorectal malformations in children. Edited by Holschneider AM, Hutson JM. Heidelberg Springer; 2006:17-30

2. Upadhyaya VD, Gangopadhyay AN, Pandey A, Kumar V, Sharma SP, Gopal SC, Gupta DK, Upadhyaya A: Single-stage repair for rectovestibular fistula without opening the fourchette. J Pediatr Surg 2008, 43:775-779

Marc ALevitt, Alberto Pena Orphanet J Rare dis 2007;2:33

4. Helen ABrough, Ram Natrajan ;Rapid Child Health And Paediatrics

5. S Nour, D Kumar, and J A Dickson, Archieves of Diseases in Childhood,1989 16181620

6. Elhamy Bekhit, Feilim Murphy, Prem Puri, and John M. Hutson:The Clinical Features and Diagnostic Guidelines for Identification of Anorectal Malformations. . Edited by Holschneider AM, Hutson JM. Heidelberg Springer; 2006:188-189. 